\title{
DIRETRIZES CURRICULARES DA EDUCAÇÃO FÍSICA: REFORMISMO E SUBORDINAÇÃO AO MERCADO NO PROCESSO DE FORMAÇÃO
}

\section{DR. LUIZ FERNANDO CAMARGO VERONEZ}

Departamento de Ginástica e Saúde, Escola Superior de Educação Física,

Universidade Federal de Pelotas

(Pelotas - Rio Grande do Sul - Brasil)

E-mail: Ifcveronez@gmail.com

MS. LOVANE MARIA LEMOS

Programa de Pós-graduação em Educação Física, Escola Superior de Educação Física, Universidade Federal de Pelotas

(Pelotas - Rio Grande do Sul - Brasil)

E-mail: lovane.lemos@gmail.com

MS. MÁRCIA MORSCHBACHER

Programa de Pós-graduação em Educação, Faculdade de Educação,

Universidade Federal da Bahia

(Salvador - Bahia - Barsil)

E-mail:mm.edufisica@yahoo.com.br

\section{MS. VILMAR JOSÉ BOTH}

Programa de Pós-graduação em Educação, Centro de Ciências

da Educação, Universidade Federal de Santa Catarina

(Florianópolis - Santa Catarina - Brasil)

E-mail: vilmarboth@yahoo.com.br

\section{RESUMO}

As reformas educacionais ocorridas na década de 1990 objetivaram intervir na formação dos trabalhadores para torná-los aptos às demandas da mundialização do capital. Na área da Educação Física, as novas diretrizes curriculares são o resultado dessas reformas, assumindo o papel de mediar as relações entre a formação e a intervenção do professor. Este artigo, extrato de uma pesquisa bibliográfica e documental fundada no Materialismo Histórico-Dialético, analisou o processo de elaboração das Diretrizes Curriculares Nacionais para os cursos de graduação em Educação Física. Assinala-se que esses documentos legais, além de legitimar os interesses da classe social ideologicamente identificada com o capital, tendem a subsumir a formação do trabalhador em Educação Física a essa lógica.

PALAVRAS-CHAVE: Formação do trabalhador em Educação Física; reforma curricular; diretrizes curriculares nacionais; mercado de trabalho. 
Em meados dos anos 1990, no contexto da reforma do Estado e da reestruturação da organização do trabalho na formação social capitalista brasileira, tendo em vista a crise de acumulação, diversas medidas jurídico-administrativas, referenciadas em preceitos neoliberais, foram encaminhadas no âmbito da educação. Essas medidas tinham como objetivo preparar cognitivamente os trabalhadores no sentido de torná-los aptos às demandas da mundialização do capital e do processo de globalização. Subjacentes a essas medidas estavam organizações internacionais e regionais, tais como o Banco Mundial (BM) e o Banco Interamericano de Desenvolvimento (BIRD) "que condicionavam a concessão de empréstimos aos Estados nacionais [...] à implantação dessas reformas" (KRAWCZYK; VIEIRA, 20 I 0, p. I0). Entre essas, destacam-se a promulgação da Lei de Diretrizes e Bases da Educação Nacional (LDBEN), a implantação dos Parâmetros Curriculares Nacionais, a implantação das Diretrizes Curriculares para os Cursos de Graduação, entre outras.

Os cursos de Educação Física (EF), sob o impacto das reformas educacionais ocorridas nessa década, diante das novas Diretrizes Curriculares Nacionais (DCN) para a formação de Professores da Educação Básica e para os cursos de graduação em EF, elaboraram propostas curriculares que tiveram como resultado o surgimento de um trabalhador de novo tipo: ao lado do curso de licenciatura cria-se o curso de graduação, recentemente (re)batizado como bacharelado. Este fato e suas consequências, repercutiu em acalorados debates no meio acadêmico, além de ter estimulado a realização de estudos que resultaram em significativa produção cientíica, entre as quais podem ser destacadas: Taffarel (1997), Kunz et al. (1998), Catani et al. (200 I ), Tojal (2004), Felício (2007), Taffarel e Santos Júnior (20 l 0), entre outros.

Conhecer os elementos mediadores do processo de mudança curricular dos cursos de EF é fundamental para compreender os dilemas e as contradições da formação do trabalhador dessa área. Assim, o objetivo deste artigo é o de descrever e analisar o processo de elaboração das DCN para os cursos de graduação em EF. Trata-se de um extrato de uma pesquisa bibliográfica e documental mais ampla, referenciada metodologicamente no materialismo histórico e dialético, sobre a formação do trabalhador em EF.

\section{A SUBSUNÇÃO DA FORMAÇÃO DO TRABALHADOR EM EDUCAÇÃO FÍSICA AO MERCADO DE TRABALHO (TRABALHO ABSTRATO): O PROCESSO DE REFORMA CURRICULAR}

Os primeiros sinais emitidos pela área da EF, que explicitaram a preocupação existente com o processo de formação do trabalhador em EF, são constatados em fins dos anos 1970 e se dão em torno da discussão sobre a intervenção profissional 
do professor. Após alguns encontros de um grupo denominado "comunidade de especialistas", é sugerida a formação em bacharelado.

A deflagração desse processo ocorreu no momento em que uma parcela da comunidade acadêmica, influenciada por supostas demandas do mercado de trabalho, iniciou a discussão sobre as limitações que a legislação, normatizadora do curso de Licenciatura Plena, impunha à formação do trabalhador em EF, tendo em vista a expansão das possibilidades de sua atuação profissional. Nesta perspectiva:

[... ] a criação do bacharelado foi, fundamentalmente, uma resposta aos argumentos de que a formação do licenciado não vinha atendendo ao desenvolvimento das qualificações e das competências necessárias à intervenção do profissional nos diversos campos de trabalho não-escolar (KUNZ et al., 1998, p. 38).

Decorrente desses debates foi elaborado o Parecer 215/87, que trata da "reestruturação dos cursos de graduação em EF, sua nova caracterização, mínimo de duração e conteúdo" (BRASIL, 1987a), e a Resolução 03/87, que fixou "os mínimos de conteúdo e duração a serem observados nos cursos de graduação em Educação Física - Bacharelado e/ou Licenciatura Plena" (BRASIL, 1987b).

A concepção curricular na qual se assentavam esses instrumentos legais admitia a flexibilidade na formação do futuro trabalhador dessa área, antecipando, como salientou o relator das atuais diretrizes curriculares, Éfren Maranhão, a flexibilidade na organização curricular dos cursos de graduação proposta na LDBEN (BRASIL, 2004a).

Cabe ressaltar que a Resolução 03/87 e o seu respectivo parecer asseguraram a extinção do currículo mínimo, e delegaram às Instituições de Ensino Superior (IES) a responsabilidade de definir e elaborar as ementas, competências finais, carga horária e denominação das disciplinas, considerando, para tanto, as diretrizes propostas pelos referidos documentos. Entretanto, parece que a comunidade acadêmica não estava preparada para absorver, em toda a sua dimensão, os pressupostos existentes nesses documentos legais, pois se limitou, na maior parte dos casos, a implantar as disciplinas estabelecidas na referida resolução.

Não demorou muito para que a Resolução 03/87 começasse a ser criticada. Na verdade, toda a legislação relativa à educação, a partir da promulgação da Constituição Federal de 1988, foi questionada e reformulada. Em 1997, o Conselho Nacional de Educação (CNE) avaliou que:

[...] os currículos dos cursos superiores, formulados na vigência da legislação revogada pela Lei 9.394, de dezembro de 1996, em geral caracterizam-se por excessiva rigidez que advém, em grande parte, da fixação detalhada de mínimos curriculares e resultam na progressiva diminuição da margem de liberdade que foi concedida às instituições para organizarem suas atividades de ensino (BRASIL, 1997a, p. I). 
Para encaminhar o processo de elaboração das diretrizes curriculares da EF foi criada uma nova comissão, denominada Comissão de Especialistas de Ensino em EF (COESP-EF), no âmbito do CNE que, segundo a própria, "procurou aprimorar a Resolução 03/87, bem como corrigir algumas distorções constatadas ao longo desses doze anos de vigência" (KUNZ et al., 1998, p. 37).

Embora se tenha tentado ampliar a base de participação, convocando-se as IES para colaborarem com sugestões às Novas Diretrizes Curriculares para os Cursos de Graduação em EF, por meio de editais publicados no Diário Oficial da União, apenas 28 instituições atenderam ao chamado.

A sistematização realizada pela COESP-EF resultou no documento denominado "Novas Diretrizes Curriculares para os Cursos de Graduação em Educação Física: Justificativas - Proposições - Argumentações", datado de 23 de abril de 1999 e encaminhado às IES para análise e discussão. Esse documento propunha superar as contradições existentes na Resolução 03/87 referente à conceituação/concepção de bacharelado e licenciado, eliminar estas formas de graduação, substituindo-as por outra com "uma sólida formação geral e uma sólida formação em nível de aprofundamento em um campo definido de aplicação profissional” (KUNZ et al., 1998, p. 4I).

Na proposta estavam previstos dois núcleos de conhecimentos: I) conhecimento identificador da área, composto pelo núcleo de formação básica (conhecimento sobre o homem e sociedade, sobre o corpo humano e seu desenvolvimento e científico-tecnológico) e pelo núcleo de formação específica (conhecimento sobre cultura do movimento humano, didático-pedagógicos e técnico-funcionais aplicados) e; 2) conhecimento identificador do tipo de aprofundamento. De acordo com esse documento, seria no nível de aprofundamento que o aluno definiria seu campo de atuação profissional: docência na educação básica/licenciatura, condicionamento/ treinamento físico, atividades físico-esportivas de lazer, gestão/administração de empreendimentos físico-desportivos, esporte, aptidão física/saúde/qualidade de vida ou ainda outro campo de atuação "emergente" (KUNZ et al., 1998). Essa proposta não tinha a intenção de mudar a concepção anterior, apenas "buscar uma denominação mais esclarecedora" (KUNZ et al., 1998).

$O$ título conferido ao formado seria o de Graduado em EF, com um determinado tipo de aprofundamento. É possível observar, de forma explícita, que a intervenção do trabalhador da área de EF deve estar submetida às leis do mercado:

Não cabe um documento dessa natureza estabelecer e delimitar, pontualmente, os campos de atuação profissional, em função do tipo de aprofundamento cursado pelo graduado. Cabe ao mercado de trabalho a aos próprios conselhos profissionais regularem esta questão. (KUNZ et al., 1998, p. 7). 
Também se observa a fragmentação do conhecimento que constituiria a formação dos egressos dos cursos. Sob a despretensiosa justificativa de "apenas mudar o nome das partes que deverão compor o currículo", propôs-se uma nova estruturação dos conhecimentos, fragmentados em maior número de categorias.

Os documentos citados expõem com clareza a perspectiva com a qual trabalhou a referida comissão. Ficou evidente a opção, a visão de mundo, as concepções, enfim, o lado do qual se colocava a COESP-EF. As propostas elaboradas, contrariando até mesmo o discurso retórico comumente aceito, não foram neutras, desinteressadas, plurais, articuladas em função do que seria o melhor para a sociedade (bem-comum) como, por suposto, caberia ao agente público, papel que a COESP-EF cumpria naquele momento. Pelo contrário, foi parcial, posicionada, ideológica, radical em defesa do mercado, dos interesses de grupos que defendem o mercado como o elemento mediador das relações sociais.

Quando a versão definitiva da proposta de diretrizes curriculares ficou pronta, entrou em vigor uma nova política para os cursos de graduação para formação de professores da Educação Básica. Um conjunto novo de regras foi estabelecido pelo CNE para a elaboração das novas diretrizes curriculares. Destacamos o Parecer CNE/CP 2 I/200 I que "estipula a duração e carga horária dos cursos de Formação de Professores da Educação Básica, em nível superior, curso de licenciatura, de graduação plena" (BRASIL, 200 I c); o Parecer CNE/CES 583/200 I que dá "orientação para as diretrizes curriculares dos cursos de graduação” (BRASIL, 200 l a); o Parecer CNE/CP 09/200 I sobre as "Diretrizes Curriculares Nacionais para a Formação de Professores da Educação Básica, em nível superior, curso de licenciatura, de graduação plena" (BRASIL, 200 I b); a Resolução CNE/CP 0 I/2002 que "institui Diretrizes Curriculares Nacionais para a Formação de Professores da Educação Básica, em nível superior, curso de licenciatura, de graduação plena" (BRASIL, 2002a); e a Resolução CNE/CP 02/2002 que "institui a duração e a carga horária dos cursos de licenciatura, de graduação plena, de formaçãa de professores da Educação Básica em nível superior" (BRASIL, 2002b).

Todo esse conjunto legal, elaborado sob forte indução externa do BM e do BIRD (KRAWCZYK; VIEIRA, 20 I0), trouxe uma nova concepção de formação do trabalhador da área de EF. O Parecer CNE/CP 09/200I, por exemplo, definia que os cursos de licenciatura deveriam ter currículos próprios que não se confundissem com os de bacharelado ou "com a antiga formação de professores que ficou caracterizada como modelo 3+ I" (BRASIL, 200 l b, p. 6). Assim, a fragmentação da formação do trabalhador em EF foi consolidada com a diferenciação em dois cursos com diferentes currículos. Por seu lado, o Parecer CNE/CP 583/200 I estipulava que as atividades obrigatórias não poderiam exceder $50 \%$ da carga horária total dos 
cursos. Abriu-se, assim, a possibilidade de flexibilização curricular, de forma que os cursos oferecessem disciplinas de acordo com as mudanças do mercado ou, como se observou nesses documentos, de acordo com os novos campos de formação emergentes na sociedade.

A partir disso, o CNE reiniciou o processo de elaboração das diretrizes curriculares dos cursos de graduação em EF, promovendo audiências públicas e convocando IES que ofereciam formação nos níveis de bacharelado e de licenciatura em EF. Nesse momento, o Conselho Federal de Educação Física (CONFEF) passou a ser o interlocutor privilegiado do CNE, participando ativamente dessas audiências.

Esse agente, com o consentimento e apoio do CNE, organizou fóruns regionais para discutir e propor subsídios para a formulação das novas diretrizes nacionais para os cursos de graduação em EF. Dos fóruns realizados, apenas o do Rio de Janeiro e do Rio Grande do Sul não elaboraram propostas. $\bigcirc$ primeiro adotou a proposta elaborada pela COESP-EF e o segundo manteve-se fiel à Resolução 03/87.

O Colégio Brasileiro de Ciências do Esporte (CBCE) também organizou um fórum para discutir a formação profissional na EF brasileira. No documento que elaborou, o CBCE propôs que a organização curricular dos cursos de EF tivesse uma perspectiva multidisciplinar, pois reconheceu:

[... ] ser imperiosa a incorporação da compreensão do caráter multidisciplinar que caracteriza a formação e intervenção profissional/acadêmica na Educação Física, como também da identificação da necessidade da presença de conhecimentos originários tanto do campo das Ciências Biológicas/Saúde como no das Ciências Humanas/Sociais, das Ciências Físicas, da Filosofia e das Artes na corporificação da totalidade do processo formativo do profissional (COLÉGIO, 2002, p. I).

A concepção de currículo apresentada pelo CBCE era avançada e destoante dos grupos conservadores que também participavam do processo. O CBCE partia de uma concepção de currículo que o considerava como "um fenômeno histórico, resultado das relações sociais, políticas e pedagógicas que se expressam na organização dos saberes vinculados à formação do ser humano" (COLÉGIO, 2002, p. 1). Porém, de forma contraditória, assumia o discurso sobre a flexibilização dos currículos, do caráter competitivo e em expansão do mercado de trabalho, ao mesmo tempo em que advogava "a necessidade de uma concepção crítico-superadora da realidade humana, social, política e econômica do país” (COLÉGIO, 2002, p. I).

O CBCE também absorvia, naquele momento, o discurso retórico assentado no conceito de competências, propondo que o currículo se organizasse em "competências gerais" e "competências específicas", embora salientasse que "a visão de competência não pode ser compreendida e nem reduzida às dimensões do fazer, do saber fazer ou do saber intervir" (COLÉGIO, 2002, p. I). 
O que o CBCE tentou fazer foi dar uma nova roupagem a uma categoria fundamental da dialética materialista, qual seja, a de práxis social, assumindo uma postura "eclética" e não enfrentando as contradições existentes no interior de sua comunidade. O discurso assentado na categoria competência, além de renegar o conhecimento histórico e socialmente produzido, é voltado unicamente para a adaptação ao mercado de trabalho e à captura acrítica da subjetividade do trabalhador, objetivando subsumi-la à lógica do trabalho abstrato. "Competência" é a categoria que "embalou" a proposta institucional do governo federal ao reestruturar as diretrizes curriculares dos cursos de graduação, excessivamente demarcado pelo discurso neoliberal.

Todo esse trabalho resultou na elaboração do Parecer CNE/CES I 38/2002, aprovado em 03 de abril de 2002, que instituía "as Diretrizes Curriculares Nacionais do Curso de Graduação em Educação Física" (BRASIL, 2002b). Esse parecer conjugou diversas propostas dos diferentes grupos de interesses que participaram do processo. $\mathrm{Na}$ análise de mérito, pôde-se observar a vinculação do perfil profissional às competências, habilidades e conteúdos e sua associação às demandas de qualidade, eficiência e resolutividade. Na perspectiva neoliberal, tais expressões são conceitos utilizados nos discursos daqueles que fazem a apologia do mercado como elemento mediador das relações humanas. Competências, habilidades, eficiência, qualidade, entre outros, apropriados sob a égide do trabalho abstrato, são os novos quesitos fundamentais para se adaptar a um mercado de trabalho que, ao intensificar a exploração e ampliar a extração de mais-valia, se mostra cada vez mais competitivo, exigente e excludente.

O Parecer CNE/CES 138/2002 absorveu a nomenclatura proposta pelo CBCE, dividindo-as em competências gerais (atenção à saúde, atenção à educação, tomada de decisões, comunicação, liderança, planejamento, supervisão e gerenciamento e educação continuada) e competências e habilidades específicas (sólida formação nas áreas de conhecimento que formam a identidade do curso, estar capacitado para intervir em todas as dimensões de seu campo, atuar em atividades físicas/motricidade humana/movimento humano, entre outros).

Embora esse parecer tenha sido aprovado, a decorrente resolução jamais o foi. $\mathrm{O}$ CNE, ao intentar absorver propostas de todos os grupos de interesse que haviam participado do processo, acabou por não acolher nenhum deles e, por isso, o documento resultante não representou a construção de um consenso na área e, tampouco, dos movimentos a ela vinculados. $\bigcirc$ único agente que o acatava e o defendia foi o CONFEF, pois dizia que o mesmo tinha sido aprovado por aqueles que eram responsáveis pela formação dos graduados, ou seja, os dirigentes das IES. Sua reação a não aprovação deste documento pode ser observada na Revista Educação Física, vinculada ao CONFEF, em um artigo elaborado por um de seus dirigentes. Escreve Tojal (2004, p. 2) que a: 
[... a ação política de componente de Órgão Público Federal, por razão meramente política, conjunta com a gestão de ex-integrantes da comissão de especialistas da SESU/MEC - COESP-EF, que entendiam que a proposta de Diretrizes Curriculares para a Educação Física, por eles elaborada e encaminhada para a análise do relator, não havia sido considerada, e assim gestionaram visando descaracterizar as recomendações feitas pelo parecer CNE/CES $0138 / 02$, construídas por aqueles que detêm realmente a responsabilidade pelo desenvolvimento da preparação, no caso, os dirigentes das IES formadoras.

É importante resgatar a verdade dos fatos, pois no histórico desenvolvido no Parecer CNE/CES 058/2004, que institui finalmente as diretrizes curriculares, está escrito que foi o CONFEF que solicitou a não homologação do Parecer CNE/ CES 138/2002. O fato que corresponde à realidade foi o seguinte: por meio de uma solicitação de integrantes do Ministério do Esporte (ME), que assumiam sua estrutura a partir da posse do governo pelo Presidente Lula em 2003, o CNE não aprovou a resolução que materializaria as novas diretrizes curriculares dos cursos de EF. Este fato só viria a ocorrer treze meses depois, após o estabelecimento de um novo processo de discussão sobre o assunto na comunidade acadêmica.

Atendendo solicitação do CNE, entre os meses de janeiro e fevereiro de 2003, o ME constituiu um grupo de trabalho com integrantes de seu quadro técnico, do CBCE e de IES, encarregado de propor um documento alternativo ao Parecer CNE/CES 138/2002. O documento elaborado por este grupo serviu como referência para a elaboração da proposta de diretrizes curriculares de outra Comissão de Especialistas em Educação Física (Portaria n. 1985 - DOU de 2 I/07/2003) constituída pelo MEC. Esta comissão deveria "analisar e propor reformulações a respeito das premissas conceituais, do rol prescritivo das competências e habilidades e da estrutura curricular dos campos de conhecimento" (BRASIL, 2003a) e encaminhar uma nova proposta de diretrizes curriculares que respondesse às críticas elaboradas ao Parecer CNE/CES 138/2002. Esta nova comissão contou com representantes do CBCE, CONFEF, INEP (Instituto Nacional de Estudos e Pesquisas Educacionais) e SESu (Secretaria de Educação Superior).

A referida comissão resgatou a categoria "conhecimento", em detrimento de "competências", e propôs que o currículo para o curso de graduação em EF fosse constituído por Conhecimentos de Formação Ampliada (constituído pelas dimensões da relação ser humano-sociedade, biológica do corpo humano, produção do conhecimento); Conhecimentos Identificadores da EF (constituída pelas dimensões culturais do movimento humano, técnico-instrumental e pedagógica) e Conhecimentos do Campo de Intervenção da EF (compreendidos como conjunto de fundamentos específicos voltados para a elaboração, implantação, implementação e avaliação de ações acadêmico-profissionais em núcleos temáticos de aprofundamento). 
A proposta dessa comissão defendia ainda que o Curso de Graduação em EF deveria ser integralizado "respeitando o mínimo de duração e carga horária de 4 anos e de 2.800 horas, respectivamente" (BRASIL, 2003b, p. 2). Esta proposta definia também os percentuais de carga horária para cada um daqueles conhecimentos: 30\% para Conhecimento de Formação Ampliada, 40\% para Conhecimentos Identificadores da EF e 30\% para Conhecimentos do Campo de Intervenção da EF. O estágio curricular teria 400 horas, sendo que $60 \%$ desta carga deveria ser cumprida em diferentes campos de intervenção da EF ao longo do curso e 40\% no campo de intervenção vinculado ao núcleo temático de aprofundamento. No que se refere à Formação de Professores da Educação Básica, a proposta limitou-se a dizer que ela deveria obedecer à legislação específica emanada do CNE (BRASIL, 2003b, p. 2).

O conjunto de normas as quais esta comissão deveria obedecer - mesmo constituída por representantes que expressavam a diversidade dos grupos de interesses existente na área - impediu que ela elaborasse um trabalho que superasse as contradições detectadas na formação do bacharel e do licenciado em EF, já intensamente criticadas pela comunidade acadêmica. A comissão foi obrigada a manter a fragmentação da área em dois cursos - licenciatura e bacharelado -, a flexibilização dos conteúdos, a limitação de disciplinas obrigatórias, o aligeiramento do curso, reduzindo a carga horária mínima a 2800 horas, entre outros. Em síntese, os parâmetros estipulados engessaram o trabalho da comissão, impedindo que se avançasse à formação para além da subordinação ao mercado.

No findar do ano de 2003, o CNE convocou uma audiência pública para selar o suposto consenso estabelecido em torno das novas diretrizes curriculares. Nesta audiência, representantes da Linha de Estudos e Pesquisa em Educação Física \& Esporte e Lazer (LEPEL), vinculado à Universidade Federal da Bahia e de representantes da Executiva Nacional dos Estudantes de Educação Física (ExNEEF), manifestaram-se contrários ao trabalho realizado pela comissão, denunciando o falso consenso que a mesma representava (TAFFAREL, 2003). Essa entidade considerou a nova legislação um retrocesso para a área da $E F$, tendo em vista que tal proposta subsume a formação do trabalhador ao capital. Taffarel (2003), no relato realizado sobre essa audiência, salienta que a ExNEEF propõe, como forma de superar as contradições presentes no documento apresentado, a Licenciatura Ampliada e reivindica que o processo de construção e de discussão das DCN seja ampliado para a comunidade acadêmica e a sociedade em geral.

Em seu conjunto, o documento resultante de todo este processo - Parecer CNE/CES 058/2004 - não difere em essência do trabalho realizado pela comissão instituída para tal finalidade. A estrutura curricular permanece a mesma, apenas retirando a expressão "conhecimento" e mantendo "formação ampliada" e "formação 
específica", com as mesmas dimensões. No entanto, a categoria "competência" foi mantida no corpo do parecer e da resolução, sendo definida no Art. $6^{\circ}$, onde se lê: "as competências de natureza político-social, ético-moral, técnico-profissional e científica deverão constituir a concepção nuclear do projeto pedagógico de formação do graduado em Educação Física" (BRASIL, 2004b, p. 2).

Portanto, o referido parecer segue à risca as referências estipuladas pelos marcos legais para a elaboração de diretrizes curriculares e não representa nenhum avanço mais significativo em direção a um processo de formação capaz de satisfazer as múltiplas necessidades por EF, esporte e lazer, oriundas de todos os segmentos da sociedade, em especial, da classe trabalhadora.

O estabelecimento do propalado consenso que se firmou em torno do Parecer CNE/CES 058/2004 representa um novo estágio das relações entre governo e movimentos organizados da sociedade civil na área da EF. A postura reativa, resistente e crítica encontrada em alguns destes movimentos antes da ascensão do governo Lula, desapareceu com a ocupação deste no cargo de Presidente da República. Muitos daqueles que estavam à frente destes movimentos foram incorporados à estrutura institucional do Estado. É certo que no caso de alguns, esta incorporação foi mediada pela crença de que o governo Lula representava a possibilidade de se estabelecer novas relações na sociedade, que incorporasse demandas extraídas da esfera de interesses das classes trabalhadoras. Os primeiros anos desse governo demonstrariam que isso seria impossível.

No caso específico das diretrizes curriculares dos cursos de graduação e de formação de professores, pode-se observar que o processo que se estabeleceu durante o governo Lula seguiu as normas estabelecidas no governo anterior. Não houve movimento para substituí-las por outras, de forma que fosse possível elaborar novas diretrizes pautadas por perspectivas mais avançadas e não atreladas aos interesses do mercado.

O CBCE, que condensava os interesses dos movimentos críticos no âmbito da EF, assumiu uma perspectiva colaborativa com o atual governo, eximindo-se de Ihe fazer críticas e optando por combater posições pontuais com as quais possuía divergências, com outros agentes sociais que participavam do processo, em especial, - CONFEF. O CBCE, conforme está disposto no histórico do Parecer CNE/CES 058/2004, contentou-se em "aprimorar" o que já estava destinado às diretrizes curriculares dos cursos de graduação em EF.

Os únicos agentes sociais participantes do processo, e que optaram por não aderir à comissão que encaminharia a versão definitiva do Parecer CNE/CES 058/2004 e denunciar o falso consenso que havia se estabelecido em torno dela, foi a EXNEEF e a LEPEL/UFBA. 
Este artigo, a partir da descrição e análise do processo de elaboração das DCN para os cursos de graduação em EF, permitiu identificar as relações de determinação dialética que se estabeleceram - e que se estabelecem - entre a formação do trabalhador em EF e as mudanças na organização do trabalho na formação social capitalista brasileira.

Evidenciou-se que o ideário neoliberal, que na década de 1990 pautou as mudanças na organização do trabalho, teve influência determinante no processo de reestruturação das DCN para os cursos de graduação em EF. Na verdade, esse processo de reestruturação, tal como ocorreu em todos os cursos de graduação, atendendo quase que completamente às recomendações dos organismos internacionais (sobretudo, BM e BIRD), foi encaminhado com o objetivo de adaptar as políticas de formação às demandas provenientes da esfera do novo e precário mundo do trabalho.

No âmbito da EF, tais demandas foram acolhidas por aqueles que hegemonizaram o processo de construção das diretrizes curriculares e determinaram sua reestruturação a partir dos interesses e necessidades das classes sociais ideologicamente identificadas com o capital. Tendo isso como referência, propuseram a fragmentação do curso e do conhecimento a ser tratado no âmbito deste (derivando da antiga formação em licenciatura plena e técnico em desportos os cursos de licenciatura e bacharelado em EF), a flexibilização, o aligeiramento e a decorrente precarização da formação.

Tal como ocorreu em outras áreas, propôs-se uma nova formação visando a "profissionalização" da EF e a criação de trabalhadores "aptos" a submeterem-se às condições que o "novo" mercado oferecia, quais sejam, a superexploração do trabalho, a impossibilidade de acesso a direitos sociais e trabalhistas, a baixa remuneração, entre outros. Além disso, pretendeu-se a formação de um trabalhador com capacidade de reproduzir acriticamente o discurso acoplado neste contexto: da necessidade de polivalência, de se estar preparado para competir no mercado, de ser o melhor para obter os melhores lugares no mercado, de ser mais competente, entre outros.

A superação das contradições evidenciadas nas DCN requer a organização dos trabalhadores em EF em função de outro projeto de formação e de sociedade. A formação desse trabalhador não pode estar atrelada aos interesses mercantis e privativistas do capital. Ela deve ser generalista, omnilateral e ter o trabalho como princípio educativo. Para tanto, as relações sociais assentadas na divisão social do trabalho, na propriedade privada dos meios de produção e mediadas pelo "mercado" também devem ser superadas e ter como horizonte a construção de uma sociedade justa, igualitária e democrática. 


\section{Physical Education Curriculum Guidelines: Reform and Subordination to the Market in the Process of Formation}

ABSTRACT: The educational reforms in the 1990s aimed to intervene in employee formation to make them fit the demands of capital globalization. In the area of Physical Education, the new curriculum guidelines are the result of these reforms, assuming the role of mediating the relationship between formation and teacher intervention. This article, an extract of bibliographical and documentary research, based on Dialectical-Historical Materialism, analyzed the process of preparing the National Curriculum Guidelines for undergraduate courses in Physical Education. It is noted that these legal documents, and to legitimize the interests of social class ideologically identified with capital, tend to subsume the worker's formation in Physical Education this logic.

KEYWORDS: Worker formation in physical education, curriculum reform, national curriculum guidelines, market work.

\section{Directrices Curriculares de la Educación Física: reforma y subordinación y el mercado en el proceso de formación}

RESUMEN: Las reformas educativas dirigidas, en la década de 1990, tuvo por objetivo intervenir en el proceso de formación de los trabajadores para adaptarlos a las exigencias de la globalización del capital. En la área de Educación Física, las nuevas directrices curriculares son el resultado de estas reformas, asumiendo el papel de la mediación de las relaciones entre la formación y la intervención del profesor. Este artículo, extracto de una investigación bibliográfica y documental basada en el Materialismo Histórico Dialéctico, se analiza el proceso de elaboración de las Directrices Curriculares Nacionales para los cursos de graduación en Educación Física. Se señala que estos documentos legales convierten en legítimos los intereses de la clase social identificada con el capital y tienden para la sujeción de la formación este trabajador en esta lógica.

PALABRAS CLAVE: Formación de trabajador en la educación física; reforma curricular; directrices curriculares nacionales; mercado de trabajo.

\section{REFERÊNCIAS}

ANTUNES, R. Os sentidos do trabalho: ensaio sobre a afirmação e a negação do trabalho. São Paulo: Boitempo, 1999.

BRASIL. Ministério da Educação. Parecer 21 5/ 1987 , de I I de março de 1987. Dispõe sobre a reestruturação dos cursos de graduação em Educação Física, sua nova caracterização, mínimos de duração e conteúdo. Brasília, 1987a. Disponível em: < http://www.dominiopublico.gov. br/download/texto/cd007078.pdf>. Acesso em: 27 ago. 2010.

BRASIL. Ministério da Educação e Cultura. Parecer CNE/CES 776/1997, de 03 de dezembro de 1997. Orientação para as diretrizes curriculares dos cursos de graduação. Brasília, 1997a. Disponível em: <http://portal.mec.gov.br/cne/arquivos/pdf/CES0776.pdf>. Acesso em: I I out. 20 I 0. 
- Parecer CNE/CES 583/2001, de 04 de abril de 200 I. Orientação para as diretrizes curriculares dos cursos de graduação. Brasília, 200 la. Disponível em: < http://portal.mec. gov.br/cne/arquivos/pdf/CES0583.pdf>. Acesso em: 12 mar. 201 l.

. Parecer CNE/CES 138/2002, de 03 de abril de 2002. Diretrizes Curriculares do Curso de Graduação em Educação Física. Brasília, 2002b. Disponível em: < http://portal. mec.gov.br/sesu/arquivos/pdf/I 3802EdFisica.pdf> . Acesso em: 27 ago. 2010.

- Parecer CNE/CES 058/2004, de 18 de fevereiro de 2004. Diretrizes Curriculares Nacionais para os cursos de graduação em Educação Física. Brasília, 2004a. Disponível em: < http://portal.mec.gov.br/cne/arquivos/pdf/2007/pces058_04.pdf_>. Acesso em: 27 ago. 2010.

. Parecer CNE/CP 09/200 I, de 08 de maio de 200 I . Diretrizes Curriculares Nacionais para a Formação de Professores da Educação Básica, em nível superior, curso de licenciatura, de graduação plena. Brasília, 200 lb. Disponível em: < http://portal.mec.gov.br/cne/arquivos/ pdf/009.pdf>. Acesso em: 27 ago. 2010.

. Parecer CNE/CP 2 I/200 I , de 06 de agosto de 200 I. Dispõe sobre a duração e carga horária dos cursos de Formação de Professores da Educação Básica, em nível superior, curso de licenciatura, de graduação plena. Brasília, 200 l c. Disponível em: < http://portal.mec.gov. br/cne/arquivos/pdf/021.pdf>. Acesso em: 27 ago. 2010.

BRASIL. Ministério da Educação e Cultura. Portaria 1985/2003, de 21 de julho de 2003. Designa Comissão de Especialistas de Ensino em Educação Física da SESu/MEC. Brasília, 2003a. Disponível em: < http://www.jusbrasil.com.br/diarios/6 19554/dou-secao-2-2 I-072003-pg-7>. Acesso em: I I out. 2010.

. Portaria 972/1997, de 22 de agosto de 1997. Trata das atribuiç̧̃̃es e critérios de composição da Comissão de Especialistas da SESu/MEC. Brasília, 1997b. Disponível em: <http://portal.mec.gov.br/sesu/arquivos/pdf/Portaria972.pdf>. Acesso em: I I out. 2010.

. Proposta Alternativa ao Parecer n. 0138 CNE/CES. Brasília, 2003b. Disponível em: <http://portal.mec.gov.br/cne/arquivos/pdf/fisica.pdf>. Acesso em: 27 ago. 2010.

- Resolução 03/1987, de 16 de junho de 1987. Fixa os mínimos de conteúdo e duração a serem observados nos cursos de graduação em Educação Física (Bacharelado e/ ou Licenciatura Plena). Brasília, 1987b. Disponível em: < http://www.ufpb.br/sods/consepe/ resolu/1990/Res0387-cfe.htm>. Acesso em: 27 ago. 2010.

- Resolução CNE/CES 07/2004, de 3 I de março de 2004. Institui as Diretrizes Curriculares Nacionais para os cursos de graduação em Educação Física, em nível superior de graduação plena. Brasília, 2004b. Disponível em: < http://portal.mec.gov.br/cne/arquivos/ pdf/ces0704edfisica.pdf>. Acesso em: 27 ago. 2010.

. Resolução CNE/CP 0 //2002, de 18 de fevereiro de 2002. Institui as Diretrizes Curriculares Nacionais para a Formação de Professores da Educação Básica, em nível superior, 
curso de licenciatura, de graduação plena. Brasília, 2002a. Disponível em: < http://portal. mec.gov.br/cne/arquivos/pdf/rcp0 I__02.pdf>. Acesso em: 27 ago. 2010.

- Resolução CNE/CP 02/2002, de 19 de fevereiro de 2002. Institui a duração e a carga horária dos cursos de licenciatura, de graduação plena, de formação de professores da Educação Básica em nível superior. Brasília, 2002b. Disponível em: < http://portal.mec. gov.br/cne/arquivos/pdf/CP022002.pdf>. Acesso em: 27 ago. 2010.

CATANI, A. M. et al. Política educacional, mudanças no mundo do trabalho e reforma curricular dos cursos de graduação do Brasil. Educação e Sociedade, Campinas, ano 22, n.75, p.67-83, ago. 2001.

COLÉGIO BRASILEIRO DE CIÊNCIAS DO ESPORTE (CBCE). Fórum sobre formação profissional na Educação Fisica brasileira: documento síntese. Campinas, 2 de março de 2002. Disponível em: <http://www.cbce.org.br>. Acesso em: 9 jul. 2009.

FELÍCIO, B. F. Em busca dos fundamentos da proposta de bacharelado em Educação Física: das justificativas teóricas do curso à atividade profissional na área. In: CONGRESSO BRASILEIRO DE CIÊNCIAS DO ESPORTE, I 5., 2007, Recife. Anais... Recife: CBCE, 2007. p. I - I0.

FRIGOTTO, G. (Org.). Educação e crise do trabalho: perspectivas de final de século. Petrópolis: Vozes, 1998.

KRAWCZYK, N. R.; VIEIRA, V. L. A reforma educacional na América Latina nos anos 90: uma perspectiva histórico-sociológica. Revista Latinoamericana de Educación Comparada, Buenos Aires, ano I, n. I, 20 I0. Disponível em: <http://saece.org.ar/relec/revistas/l/art l . pdf $>$. Acesso em: 21 jul. 201 l.

KUNZ, E. et al. Novas diretrizes curriculares para os cursos de graduação em Educação Física: justificativas - proposições - argumentações. Revista Brasileira de Ciências do Esporte, Campinas, v. 20, n. I, p. 37-47, set. 1998.

PASSET, R. A ilusão neoliberal. Rio de Janeiro: Record, 2002.

SILVA JR., J. R. Reforma universitária: a nova forma histórica das esferas pública e privada no início do Século XXI. In: ORSO, P. J. (Org.). Educação, sociedade de classes e reformas universitárias. Campinas: Autores Associados, 2007.

TAFFAREL, C. N. Z. Currículo, formação profissional na educação física \& esporte e campos de trabalho em expansão: antagonismos e contradições da prática social. Movimento, Porto Alegre, ano 4, n. 7, p. 43-51, 1997.

TAFFAREL, C. N. Z. Relato das audiências públicas no CNE dias 15 e 16 de dezembro de 2003. Disponível em: <http://www.rascunhodigital.faced.ufba.br/>. Acesso em: 23 set. 2010.

.; SANTOS JÚNIOR, C. de L. Formação humana e formação de professores de Educação Física: para além da falsa dicotomia licenciatura $x$ bacharelado. In: TERRA, D. V.; 
SOUZA JÚNIOR, M. (Org.). Formação em Educação Física \& ciências do esporte: políticas e cotidiano. São Paulo: Aderaldo \& Rothschild; Goiânia: CBCE, 20 I 0. p. 13-47.

TOJAL, J. B. A. G. Diretrizes curriculares, um pouco de história. Educação Física, Rio de Janeiro, n. 12, p. 16-18, maio 2004.

Recebido em: 28 ago. 201 I

Aprovado em: 27 dez. 2012

Endereço para correspondência: Luiz Fernando Camargo Veronez

Escola Superior de Educação Física - ESEF/UFPel

Rua Luiz de Camões, 625

Bairro Tablada

Pelotas/RS

CEP: $96055-630$ 